\title{
Enantioselective Total Synthesis of the Archaeal Lipid Parallel GDGT-0
}

\author{
Isaac D. Falk, ${ }^{1}$ Bálint Gál, ${ }^{1}$ Ahanjit Bhattacharya, ${ }^{1}$ Jeremy H. Wei, ${ }^{2}$ Paula V. Welander, ${ }^{2}$ Steven G. \\ Boxer, ${ }^{1}$ and Noah Z. Burns*,1 \\ ${ }^{1}$ Department of Chemistry, Stanford University, Stanford, California 94305 \\ ${ }^{2}$ Department of Earth System Science, Stanford University, Stanford, California 94305
}

\begin{abstract}
Archaeal glycerol dibiphytanyl glycerol tetraethers (GDGT) are some of the most unusual membrane lipids identified in nature. These amphiphiles are the major constituents of the membranes of numerous Archaea, some of which are extremophilic organisms. Due to their unique structures, there has been significant interest in studying both the biophysical properties and the biosynthesis of these molecules. However, these studies have thus far been hampered by limited access to chemically pure samples. Herein, we report a concise and stereoselective synthesis of the archaeal tetraether lipid GDGT-0 and the synthesis and self-assembly of derivatives bearing different polar groups.
\end{abstract}

Organisms belonging to the domain Archaea are ubiquitous in nature. ${ }^{1,2}$ Originally discovered in hostile conditions, these prokaryotes are now known to thrive in many terrestrial and aquatic environments. Organisms of this type are also present in the human microbiome and may have implications for human health and disease. ${ }^{3}$ Archaeal membranes contain some of the most structurally-exotic lipids known and are distinguished by three structural differences compared to the other domains of life. First, in contrast to canonical fatty acids, these lipids are isoprenoid derived. Second, the hydrophobic portions of the molecule are joined to glycerol-based headgroups by ether bonds rather than ester linkages. Finally, the glycerol headgroup features opposite stereochemistry to that found in other domains of life. ${ }^{4}$ The most distinct of these molecules are the macrocyclic bipolar glycerol dibiphytanyl glycerol tetraether (GDGT) lipids. An archetypal member of this class is GDGT-0, also referred to as isocaldarchaeol, $(\mathbf{1})^{5}$ which contains two biphytanyl diols (2, Figure 1). These molecules appear to form monolayer membranes ${ }^{6}$ and are thought to be an evolutionary adaptation to facilitate survival in the face of extreme environments. ${ }^{7}$ Specifically, it was hypothesized that these lipids promote the formation of fluid membranes which maintain their integrity under conditions of thermal and acidic stress that would compromise membranes formed from canonical lipids. ${ }^{4,7}$ For example, vesicles comprised of a mixture of GDGT lipids display anomalously low proton permeability that is maintained up to $70-80$ ${ }^{\circ} \mathrm{C}$. ${ }^{8 \mathrm{~d}}$ Based on the unique biophysical and physicochemical properties displayed by these molecules, they have garnered significant interest. ${ }^{8}$ However, likely due to challenges in isolation and separation, ${ }^{9,10 i}$ the vast majority of studies have been performed on lipid mixtures,${ }^{8}$ model lipids,${ }^{10}$ or in silico.${ }^{11}$ Studies on chemically homogenous samples of naturally occurring lipids have been highly limited. ${ }^{12}$

In addition to the intriguing physicochemical properties of these lipids, their biosynthesis is also of significant interest.
However, this remains poorly understood. ${ }^{4,13}$ There is interesting structural diversity within the GDGTs, with some members of the family incorporating five- and six-membered cycloalkanes within their hydrocarbon core as exemplified by GDGT8 (3, Figure 1). Only recently have the enzymes responsible for

Figure 1. Representative tetraether archaeal lipids $\mathbf{1}$ and $\mathbf{3}$, biphytanyl core structure $\mathbf{2}$, previous synthetic approaches, and this approach.
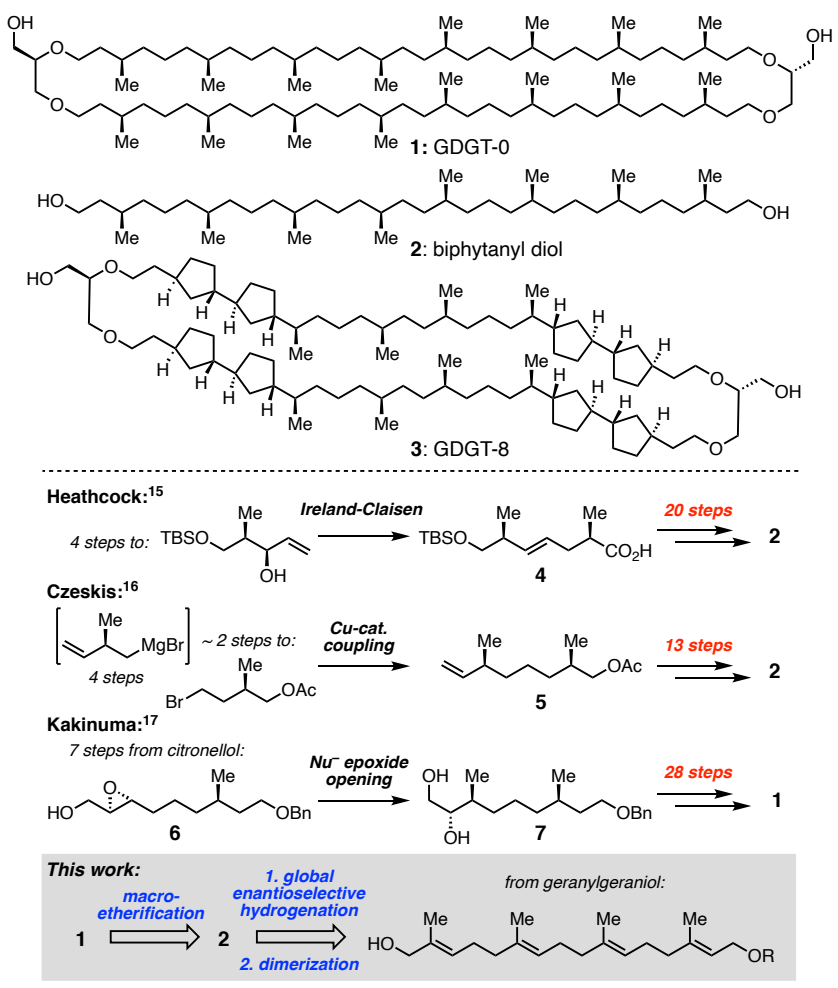


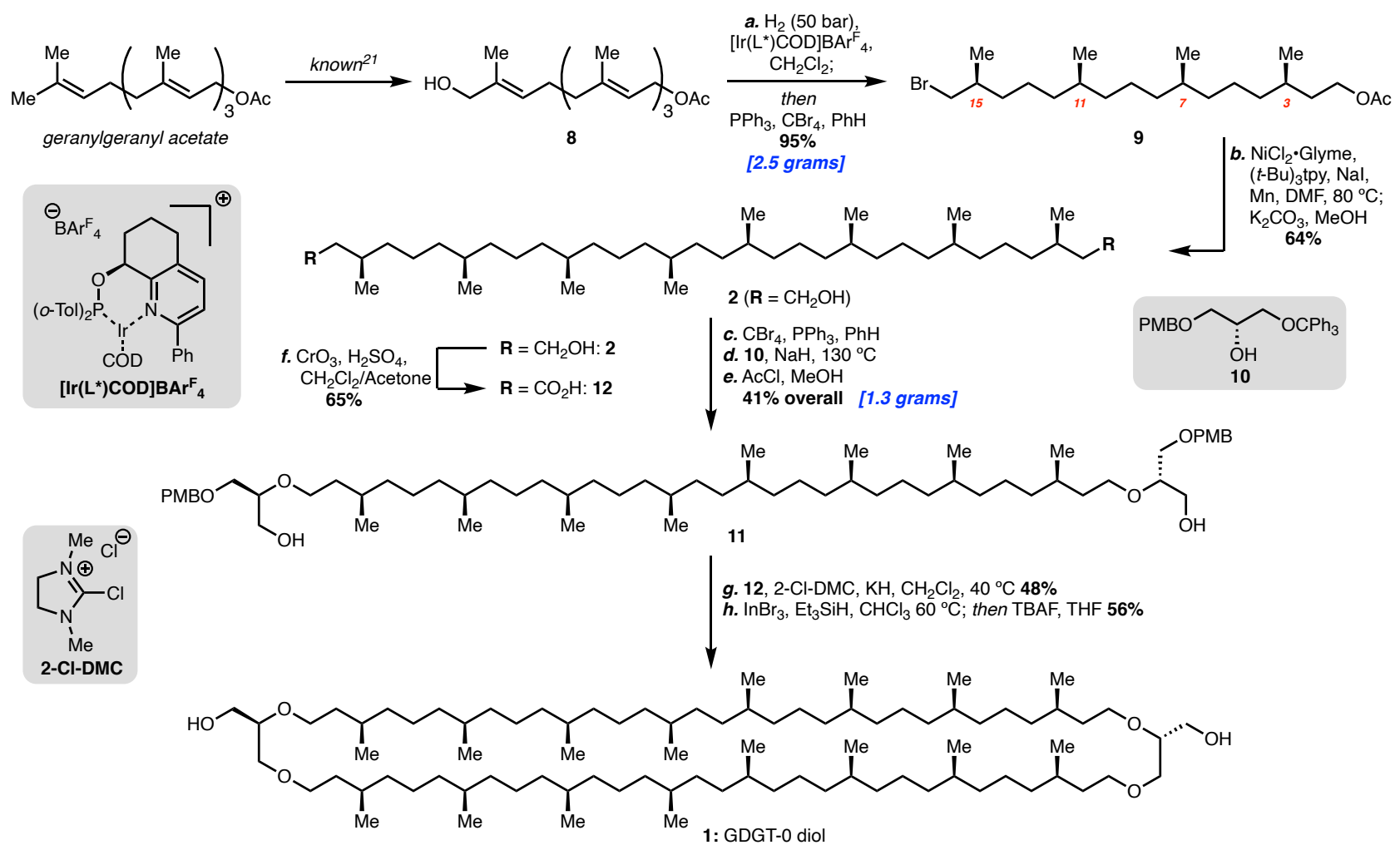

${ }^{a}$ Reagents and conditions: (a) $[\mathrm{Ir}(\mathrm{L} *) \mathrm{COD}] \mathrm{BAr}^{\mathrm{F}} 4(2.5 \mathrm{~mol} \%), \mathrm{H}_{2}\left(50\right.$ bar), $\mathrm{CH}_{2} \mathrm{Cl}_{2}, \mathrm{rt}$; $\mathrm{PPh}_{3}\left(2.3\right.$ equiv), $\mathrm{CBr}_{4}\left(2.2\right.$ equiv), $\mathrm{PhH}^{\circ}{ }^{\circ} \mathrm{C}$, 94\%; (b) $\mathrm{NiCl}_{2} \bullet$ Glyme (5 mol \%), ( $t$-bu) $)_{3}$ tpy (5 mol \%), NaI (1.0 equiv), Mn (5.0 equiv), DMF, $80{ }^{\circ} \mathrm{C} ; \mathrm{K}_{2} \mathrm{CO}_{3}(7.5$ equiv), $\mathrm{MeOH}, \mathrm{rt}, 64 \%$; (c) $\mathrm{PPh}_{3}$ (4.6 equiv), $\mathrm{CBr}_{4}$ (4.4 equiv), $\mathrm{PhH}, 0{ }^{\circ} \mathrm{C}, 84 \%$; (d) $\mathrm{NaH}$ (5.0 equiv), 10 (4.8 equiv), THF then neat, $130{ }^{\circ} \mathrm{C}, 55 \%$; (e) $\mathrm{AcCl}(3.0$ equiv), $\mathrm{MeOH}, \mathrm{CH}_{2} \mathrm{Cl}_{2}, 0{ }^{\circ} \mathrm{C}, 88 \%$; (f) Jones reagent (7.5 equiv), $\mathrm{CH}_{2} \mathrm{Cl}_{2}$, Acetone, $0{ }^{\circ} \mathrm{C}, 65 \%$; (g) 12 (2.0 equiv), 2-Cl-DMC (18.0 equiv), $\mathrm{KH}$ (16.3 equiv), DMAP (24.0 equiv), $\mathrm{CH}_{2} \mathrm{Cl}_{2}, 0{ }^{\circ} \mathrm{C}$ to $40{ }^{\circ} \mathrm{C}, 48 \%$; (h) $\mathrm{InBr}_{3}$ (ca. 0.2 equiv), $\mathrm{Et}_{3} \mathrm{SiH}\left(8.0\right.$ equiv), $\mathrm{CHCl} 3,6{ }^{\circ} \mathrm{C}$; $\mathrm{TBAF}, \mathrm{THF}$,

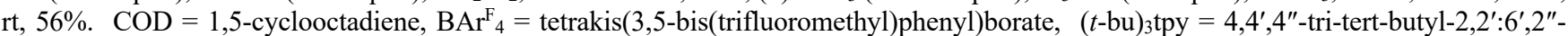
terpyridine, $\mathrm{PMB}=$ para-methoxybenzyl, 2-Cl-DMC = 2-chlorodimethylimidazolinium chloride, $\mathrm{DMAP}=4$-dimethylaminopyridine, $\mathrm{TBAF}$ $=$ tetrabutylammonium fluoride.

the formation of these cycloalkanes been identified, but the exact substrates for cyclization are still unknown. ${ }^{14}$ In vitro and in vivo studies towards investigating this biosynthesis would greatly benefit from access to pure individual GDGTs and analogues. Motivated by the aforementioned questions, we have sought to provide synthetic access to pure lipids and putative natural intermediates. Herein, we report a concise eight-step enantioselective synthesis of GDGT-0 and their functionalization to vesicle-forming amphiphiles.

Three groups have previously reported synthetic studies on GDGT- $0 .{ }^{15-17}$ The absolute and relative stereochemistry of the biphytanyl core (2) of $\mathbf{1}$ was established through the synthesis by Heathcock, which uses an enantioselective aldol-IrelandClaisen sequence to set the $s y n-1,5$ methyl stereocenters of the natural product. ${ }^{15}$ Eleven-carbon fragment 4 was then repeatedly used to construct 2 in 25 total steps. Czeskis ${ }^{16 a, 16 b}$ later joined two chiral building blocks derived from $(R)$-5-acetoxy4-methylpentanoic acid ${ }^{16 \mathrm{c}}$ via cross-coupling to $\mathbf{5}$, which was transformed into 2 in 13 steps. Shortly thereafter, Kakinuma completed the first total synthesis of macrocycle $\mathbf{1}$ from citronellol via regioselective opening of Sharpless asymmetric epoxidation product $6 .{ }^{17} \mathrm{syn}$-1,5-Dimethyl diol 7 was then elaborated into $\mathbf{1}$ in 28 steps. While successful in setting the requisite stereochemistry, these strategies suffer from numerous functional and protecting group manipulations that result in high step counts and poor scalability. The shortest total synthesis of GDGT-0 to date requires over 30 steps to complete. ${ }^{17}$

For our approach, we initially traced 1 back to biphytanyl diol 2 via a non-trivial bimolecular macroetherification that is, to the best of our knowledge, unprecedented for this ring size (Figure 1). This direct approach to macrocyclization was designed to limit the number of functional group interconversions required for $\mathrm{C}-\mathrm{C}$ bond-forming ring closures as in previous work. ${ }^{17 \mathrm{~b}, 17 \mathrm{c}}$ Furthermore, inspired by the work of Pfaltz on the asymmetric hydrogenation of isoprenes, ${ }^{19}$ it was envisioned that a global asymmetric hydrogenation of oxidized geranylgeraniol would simultaneously set all of the methyl stereocenters present in the natural product. Dimerization of the saturated building block would then enable the rapid construction of GDGT-0 via the proposed macroetherification.

In practice, the hydrogenation substrate $\mathbf{8}$ was readily prepared from geranylgeranyl acetate ${ }^{20}$ via a known allylic oxidation sequence (Scheme 1). ${ }^{21}$ Using the conditions developed by Pfaltz, we were successfully able to fully hydrogenate $\mathbf{8}$. In order to determine the stereoselectivity of this key transformation, we assayed both the triisopropylsilyl- and acetate-protected hydrogenation products (Figure 2). We found that derivatization as $\mathrm{MTPA}^{22}$ or $\mathrm{M} \alpha \mathrm{NP}^{23}$ chiral esters enabled determination of the stereoselectivity of the hydrogenated products at $\mathrm{C} 3(8.3: 1$ d.r.) and $C 15$ ( $\geq 20: 1$ d.r.), respectively. A degradation-based 
approach, performed on a silyl ether analogue, then allowed for the assignment of the innermost C7 and C11 stereocenters. Specifically, removing carbon units from either the right- or lefthalf of the molecule then allowed for determining the diastereomeric ratio at $C 7$ ( $\geq 20: 1$ d.r.) and $C 11$ ( $\geq 20: 1$ d.r.) after $M \alpha N P$ derivatization (Figure 2). Overall, the hydrogenation displayed excellent selectivity at $\mathrm{C} 7, \mathrm{C} 11$, and $\mathrm{C} 15$ and impressive but somewhat diminished selectivity at C3. Attempts to further improve this were unsuccessful, having either no or deleterious effects on the overall diastereoselectivity (See Supporting Information).

Following asymmetric hydrogenation of $\mathbf{8}$, we found that bromination could be directly carried out on the crude reaction mixture to afford bromide 9 in $95 \%$ yield. A Weix nickel-catalyzed reductive dimerization ${ }^{24}$ followed by acetate deprotection then afforded biphytanyl diol 2 in 64\% yield from 9 on gram scale. This highly efficient sequence allowed us to drastically improve upon the step count of Heathcock and Czeskis' previous syntheses. Installation of the glycerol units proved surprisingly challenging and required considerable investigation. Ultimately, it was discovered that the dibromide derived from 2 underwent double displacement with the sodium alkoxide of glycerol 10 under solvent-free conditions ${ }^{10 \mathrm{c}}$ to afford the desired product in 55\% yield. Deprotection of the trityl groups in methanolic $\mathrm{HCl}$ delivered diol 11 in $41 \%$ overall yield from 2 .

Figure 2. Chiral ester analysis of each stereocenter after global asymmetric hydrogenation.

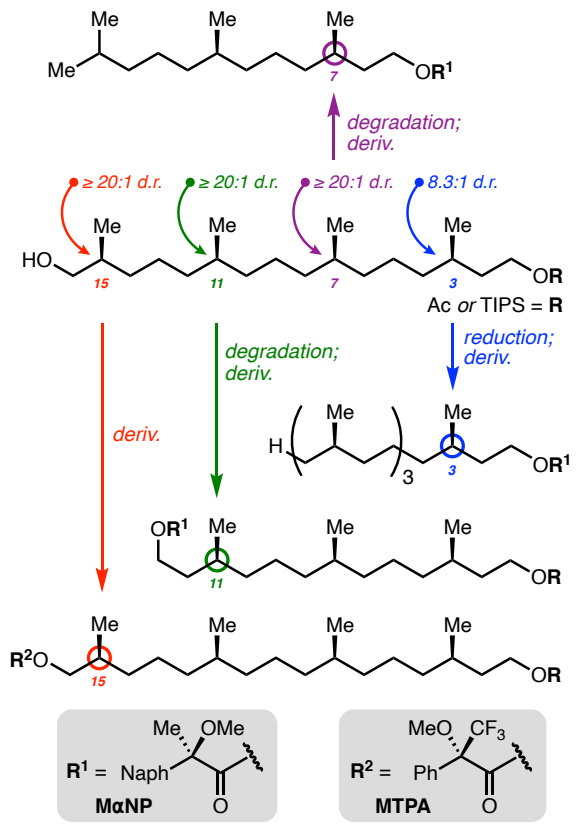

We had hoped that, through careful reaction optimization, we would be able to perform a direct bimolecular etherificationmacroetherification via Williamson-type chemistry. However, attempts to achieve these transformations with 11 and various derivatives of $\mathbf{2}$ were met with little success, affording complex mixtures of unreacted starting material, elimination side products, and other uncharacterized materials. This lack of encouraging results from a direct macroetherification led us to consider the use of more precedented macrolactonizations ${ }^{25}$ to forge our desired $\mathrm{C}-\mathrm{O}$ bonds. We envisaged that reduction of the esters to the corresponding ethers via a catalytic hydrosilylation $^{26}$ would then effect a formal macroetherification. This macrolactonization-reduction strategy represents an underutilized, yet attractive approach to macrocyclic ethers.

Jones oxidation of $\mathbf{2}$ proceeded smoothly to yield bis-carboxylic acid 12. Yamaguchi conditions ${ }^{27 a}$ were initially successful at combining $\mathbf{1 2}$ and $\mathbf{1 1}$ in the macrolactonization, ${ }^{27 \mathrm{~b}}$ providing superior results to Corey-Nicolaou ${ }^{27 \mathrm{c}}$ or Mitsunobu-type ${ }^{27 \mathrm{~d}}$ procedures. However, we found the Yamaguchi protocol performed poorly on scale, producing numerous side products, which proved difficult to separate from the desired macrocycle. After pursuing a wider range of conditions, we obtained our most promising results using a procedure employed by Fürstner in their synthesis of cycloviracin $\mathrm{B} .^{28}$ The use of dimethylimidazolinium chloride (2-Cl-DMC) ${ }^{29}$ in the presence of $\mathrm{NaH}$ and DMAP cleanly afforded the desired product in a scalable fashion. Through careful adjustments to the reaction conditions, it was found that using $\mathrm{KH}$ in lieu of $\mathrm{NaH}$ and increasing the reaction time and temperature in the presence of excess diacid $\mathbf{1 2}$ afforded the desired diolide in $48 \%$ yield. This impressively efficient double esterification-72-membered ring formation is, to the best of our knowledge, among the largest recorded macrolactonizations. ${ }^{25}$

Reduction of the esters of the macrocyclic diolide to their corresponding ethers was all that remained for our synthesis of GDGT-0 (1). After some experimentation, we discovered that the use of catalytic indium tribromide in the presence of triethylsilane accomplished the desired reductions. ${ }^{30}$ These conditions also led to serendipitous PMB-ether deprotection. Minor amounts of TES-protected $\mathbf{1}$ are formed from in situ-generated $\mathrm{Et}_{3} \mathrm{SiBr}$. Treatment of the crude reaction mixture with TBAF liberated any silyl-protected material and afforded GDGT- $0^{31}$ in $56 \%$ yield.

With the core lipid in hand, we then turned our attention toward the installation of polar headgroups for subsequent biophysical studies. Consistent with prior reports, ${ }^{12}$ phosphate headgroups are readily incorporated onto 1 to give GDGT- 0 bisphosphate 13 (Scheme 2). However, naturally occurring GDGT lipids are predominantly non- $C_{2}$-symmetric, bearing different functionality on the two glycerol units. ${ }^{4,13 a, 7 b}$ These unsymmetric natural products predominantly feature mono- and/or oligosaccharides that are either directly connected to the glycerols or via a phosphate linkage, as well as common phosphate esters and acids. Thus, we needed to develop a strategy to desymmetrize 1. As a proof of concept, this was accomplished via a double protection-monodeprotection sequence. While the efficiency of this sequence is not ideal, the only other compounds formed are bis-TBDPS-GDGT-0 and GDGT-0, both of which can be recovered. Acid-catalyzed glucosylation with glucosyl donor $\mathbf{1 4}$ followed by fluoride silyl ether cleavage afforded the monoglucosylated GDGT-0 $\mathbf{1 5}$ as a mixture of anomers. Introduction of a phosphate and global debenzylation then delivered 16. This represents the first synthesis of a natural GDGT with differentially functionalized glycerols and the first synthesis of a natural GDGT bearing a carbohydrate head group.

Motivated by the dearth of biophysical studies on homogenous GDGT lipids, we first sought to investigate the self-assembly of $\mathbf{1 3}$ and 16 into vesicles. Gentle hydration of these lipids resulted in the observation of giant unilamellar vesicles (GUVs) with uniform incorporation of fluorescently labeled lipid Texas Red-DHPE (Scheme 2B,2D). These vesicles are also capable of encapsulating water-soluble carboxyfluorescein dye (Scheme $2 \mathrm{C}, 2 \mathrm{E})$. While the self-assembly of $\mathbf{1 3}$ has been reported, ${ }^{12}$ our studies with $\mathbf{1 6}$ are the first evidence of the formation of GUVs 
from unsymmetric synthetic GDGT lipids. This discovery will enable further biophysical studies into vesicles derived from $\mathbf{1 6}$ and holds great promise for studies into other unsymmetric derivatives of 1 .

Scheme 2. Installation of Polar Headgroups and Observed Self-assembly. ${ }^{a}$

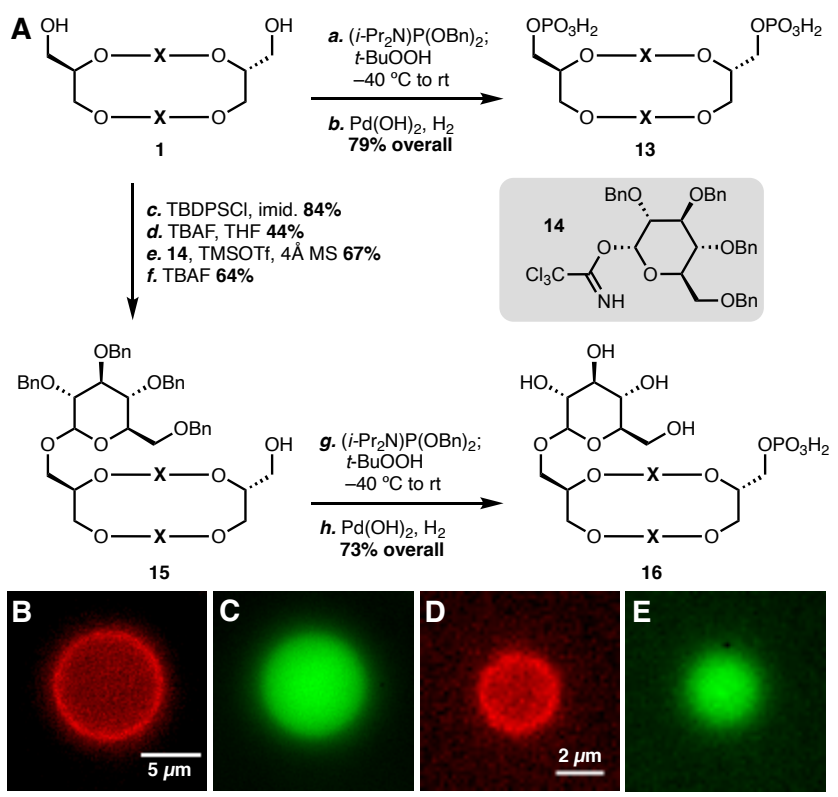

A. ${ }^{a}$ Reagents and conditions: (a) $\left(i-\mathrm{Pr}_{2} \mathrm{~N}\right) \mathrm{P}(\mathrm{OBn})_{2}$ (5.0 equiv), tetrazole (8.0 equiv), $\mathrm{CH}_{2} \mathrm{Cl}_{2}$, rt; then $t$ - $\mathrm{BuOOH}$ (20.0 equiv), -40 ${ }^{\circ} \mathrm{C}$ to rt; (b) $\mathrm{Pd}(\mathrm{OH})_{2}$, THF/EtOH, rt, 79\% overall; (c) TBDPSCl (3.0 equiv), imidazole (4.0 equiv), $\mathrm{CH}_{2} \mathrm{Cl}_{2}, \mathrm{rt}, 84 \%$; (d) TBAF (1.0 equiv), THF, rt, 44\%; (e) 14 (2.1 equiv), TMSOTf ( 0.1 equiv), $\mathrm{CH}_{2} \mathrm{Cl}_{2}, 4 \AA \mathrm{MS}, \mathrm{rt}, 67 \%$; (f) TBAF (5.0 equiv), THF, rt, 64\%; (g) $\left(i-\mathrm{Pr}_{2} \mathrm{~N}\right) \mathrm{P}(\mathrm{OBn})_{2}$ (5.0 equiv), tetrazole (8.0 equiv), $\mathrm{CH}_{2} \mathrm{Cl}_{2}, \mathrm{rt} ; t$ $\mathrm{BuOOH}$ (20.0 equiv), $-40{ }^{\circ} \mathrm{C}$ to $\mathrm{rt}$; (h) $\mathrm{Pd}(\mathrm{OH})_{2}, \mathrm{THF} / \mathrm{EtOH}, \mathrm{rt}$, $73 \%$ overall. B-E Fluorescence microscopy images of GUVs. B. 13, $0.1 \%$ TR-DHPE. C. 13, $0.5 \mathrm{mM}$ carboxyfluorescein. D. 16, $0.1 \%$ TR-DHPE. E. 16, $0.5 \mathrm{mM}$ carboxyfluorescein. TR-DHPE = Texas Red 1,2-dihexadecanoyl-sn-glycero-3-phosphoethanolamine triethylammonium salt.

We next turned our attention toward studying the phase behaviors of these synthetic lipids. While $\mathbf{1 3}$ behaved as a fluid at room temperature, $\mathbf{1 6}$ demonstrated more gel-like behavior. Differential scanning calorimetry (DSC) studies of $\mathbf{1 3}$ and $\mathbf{1 6}$ were unable to identify any endothermic transitions between $40{ }^{\circ} \mathrm{C}$ and $90{ }^{\circ} \mathrm{C}$, indicating that no significant phase transitions were observed within this temperature range. In order to further study the packing characteristics of these lipids, we measured the fluorescence spectra across various temperatures of the solvatochromic dye Laurdan incorporated into membranes of 13 and $16 .{ }^{32}$ A gradual decrease in generalized polarization occurred in both lipid samples as the temperature was increased, suggesting the membranes were becoming increasingly fluid. However, consistent with the DSC experiments, no discrete phase transitions were observed from the spectra.

A rapid and enantioselective synthesis of the archaeal tetraether lipid GDGT-0 and the synthesis and self-assembly of derivatives bearing different polar head groups is reported. The approach relied on the use of a global asymmetric hydrogena- tion to set all syn-1,5 methyl stereocenters present in the hydrocarbon core. A macrolactonization-hydrosilylation sequence was then employed to construct the natural product via a formal macroetherification. Subsequent desymmetrization enabled the first synthesis of an unsymmetric GDGT-0 bearing two different polar headgroups. Finally, phase transition and self-assembly studies provided evidence that these synthetic lipids selfassemble into fluid giant unilamellar vesicles. This highly efficient approach to GDGT-0 will enable future studies into both the unique biophysics and biosynthesis of this molecule and its derivatives.

\section{ASSOCIATED CONTENT}

\section{Supporting Information}

The Supporting Information is available free of charge on the ACS Publications website.

Experimental procedures, characterizations, and spectral data (PDF)

\section{AUTHOR INFORMATION}

\section{Corresponding Author \\ *nburns@stanford.edu}

\section{Author Contributions}

The manuscript was written through contributions of all authors. All authors have given approval to the final version of the manuscript.

\section{Funding Sources}

This work was funded by the National Science Foundation (CAREER CHE-1846512 to NZB, MCB-1915727 to SGB), the National Institutes of Health (GM118044 to SGB), NASA (19EXO19-0050 to PVW), and the Center for Molecular Analysis and Design at Stanford (graduate fellowship for IDF). Part of this work was performed at the Stanford Nano Shared Facilities (SNSF), supported by the National Science Foundation (ECCS-1542152).

\section{ACKNOWLEDGMENT}

We acknowledge Dr. S. Lynch (Stanford) for assistance with NMR spectroscopy and to the University of Illinois Urbana-Champaign for assistance with mass spectroscopy. We are grateful to Prof. Andreas Pfaltz (University of Basel) for a kind donation of iridium catalyst and for help regarding its preparation, and to Dr. Eugene Kwan (Merck) for early assistance with NMR studies.

\section{REFERENCES}

(1) (a) Woese, C. R.; Fox, G. E. Phylogenetic structure of the prokaryotic domain: The primary kingdoms. Proc. Natl. Acad. Sci. USA. 1977, 74, 5088-5090. (b) Woese, C. R.; Kandler, O.; Wheelis, M. L. Toward a natural system of organisms: Proposal for the domains Archaea, Bacteria, and Eucarya. Proc. Natl. Acad. Sci. USA. 1990, 87, 4576-5479.

(2) (a) Delong, E. F.; Everything in moderation: Archaea as 'nonextremophiles'. Curr. Op. Genet. Dev. 1998, 8, 649-654. (b) Schouten, S.; Hopmans, E. C.; Pancost, R.D.; Sinninghe Damsté, J. S.; Widespread occurrence of structurally diverse tetraether membrane lipids: Evidence for the ubiquitous presence of low-temperature relatives of hyperthermophiles. Proc. Natl. Acad. Sci. USA 2000, 97, 1442114426.

(3) Bang, C.; Schmitz, R. A. Archaea associated with human surfaces: Not to be underestimated. FEMS Microbiology Reviews. 2015, 39, 631-648.

(4) (a) De Rosa, M.; Gambacorta, A. The lipids of archaebacteria. Prog. Lipid Res. 1988, 27, 153-175. (n) Gambacorta, A.; Gliozzi, A.; 
De Rosa, M. Archaeal lipids and their biotechnological applications. World Journal of Microbiology and Biotechnology. 1995. 11, 115-131. (b) Ulrih, N. P.; Gmagner, D.; Raspor, P. Structural and physicochemical properties of polar lipids from thermophilic archaea. Appl. Microbiol. Biotechnol. 2009, 84, 249-260. (c) Chong, P. L.G. Archaeabacterial bipolar tetraether lipids: Physico-chemical and membrane properties. Chemistry and Physics of Lipids. 2010, 163, 253-265. (d) Schouten, S.; Hopmans, E. C.; Sinninghe Damsté, J. S. The organic geochemistry of glycerol dialkyl glycerol tetraether lipids: A review. Organic Geochemistry. 2013. 54, 19-61. (e) Caforio, A.; Driessen, A. J.M. Archaeal phospholipids: Structural properties and biosynthesis. Biochimica et Biophysica Acta. 2017. 1862, 1325-1339.

(5) (a) De Rosa, M.; Gambacorta, A.; Bu'Lock, J. D. Cyclic diether lipids from very thermophilic acidophilic bacteria. J. Chem. Soc., Chem. Commun. 1974, 543-544. (b) Mayberry-Carson, K. J. Langworth, T. A.; Mayberry, W. R.; Smith, P. F. A new class of lipopolysaccharide form Thermoplasma acidophilum. Biochim. Biophys. Acta. 1974, 360, 217-229. (c) de Roas, M.; Gambacorta, A.; Bu'Lock, J. D. The caldariella group of extreme thermoacidophile bacteria: Direct comparison of lipids in sulfolobus, thermoplasma, and the MT strains. Phytochemistry. 1976, 75, 143-145. (d) Langworthy, T. A. Long-chain diglycerol tetraethers from Thermoplasma acidophilum. Biochim. Biophys. Acta, 1977, 487, 37-50. (d) De Rosa, M.; De Rosa, S.; Gambacorta, A.; Minale, L.; Bu'Lock, J. D. Chemical structure of the ether lipids of thermophilic acidophilic bacteria of the Caldariella group. Phytochemistry. 1977, 16, 1961-1965. (e) Tornabene, T. G.; Langworthy, T. A. Diphytanyl and dibiphytanyl glycerol ether lipids of methanogenic archaebacteria. Science. 1979, 203, 51-53. (f) Kushwaha, S. C.; Kates, M.; Sprott, G. D.; Smith, I. C. P. Novel polar lipids from the methanogen Methanospirillum hungatei GP1. Biochim. Biophys. Acta. 1981, 156-173.

(6) (a) De Rosa, M.; Gambacorta, A.; Nicolaus, B. A new type of cell membrane, in thermophilic archaeabacteria, based on bipolar ether lipids. Journal of Membrane Science. 1983, 16, 287-294. (b) Elferink, M. G.; de Wit, J. G.; Demel, R.; Driessen, A. J.; Koning, W. N. Functional reconstitution of membrane proteins in monolayer liposomes from bipolar lipids of Sulfolobus acidocaldarius. Journal of Biological Chemistry. 1992, 267, 1375-1381.

(7) (a) Valentine, D. L. Adaptations to energy stress dictate the ecology and evolution of the Archaea. Nature Reviews Microbiology. 2007, 5, 316-323. (b) Oger, P. M.; Cario, A. Adaptation of the membrane in archaea. Biophysical Chemistry. 2013, 183, 42-56. (n) Siliakus, M. F.; van der Oost, J.; Kengen, S. W. M. Adaptations of archaeal and bacterial membranes to variations in temperature, $\mathrm{pH}$ and pressure. Extremophiles. 2017, 21, 651-670.

(8) (a) Gliozzi, A.; Paoli, G.; De Rosa, M.; Gambacorta, A. Effect of the isoprenoid cyclization on the transition temperature of lipids in thermophilic archaebacteria. Biochim. Biophys. Acta. 1983, 735, 234 242. (b) Kao, Y. L.; Chang, E. L.; Chong, P. L.-G. Unusual pressure dependence on the lateral motion of pyrene-labeled phosphatidylcholine in bipolar lipid vesicles. Biochemical and Biophysical Research Communications. 1992, 188, 1241-1246. (c) Chang, E. L. Unusual thermal stability of liposomes made from bipolar tetraether lipids. Biochem. Biophys. Res. Commun. 1994, 202, 673-679. (d) Elferink, M. G. L.; de Wit, J. G.; Driessen, A. J. M.; Konings, W. N. Stability and proton permeability of liposomes composed of archaeal tetraether lipids. Biochim. Biophys. Acta. 1994, 1193, 247-254. (e) van de Vossenberg, J. L. C. M.; Ubbink-Kok, T, Elferink, M. G. L.; Driessen, A. J. M., Koning, W. N. Ion permeability of the cytoplasmic membrane limits the maximum growth temperature of bacteria and archaea. Molecular Microbiology. 1995, 18, 925-932. (f) Dante, S.; De Rosa, M.; Maccioni, E.; Morana, A.; Nicolini, C.; Rustichelli, F.; Troitsky, V. I.; Yang. B. Thermal Stability of bipolar lipid Langmuir-Blodgett films by X-ray diffraction. Mol. Cryst. Liq. Cryst. 1995, 262, 191-207. (g) Komatsu, H.; Chong, P. L.G.; Low permeability of liposomal membranes composed of bipolar tetraether lipids from thermoacidophillic archaeabacterium Sulfolobus acidolocarius. Biochemistry. 1998, 37, 107-115. (h) Jarrell, H. C.; Zukotynski, K. A.; Sprott, G. D. Lateral diffusion of the total polar lipids from Thermoplasma acidophilum in multilamellar liposomes. Biochim. Biophys. Acta. 1998, 1369, 259266. (i) van de Vossenberg, J. L. C. M.; Driessen, A. J. M.; Zillig, W.;
Konings, W. N. Bioengergetics and cytoplasmic membrane stability of the extremely acidophilic, thermophilic archaeon Picrophilus oshimae. Extremophiles. 1998, 2, 67-74. (j) Bagatolli, L.; Gratton, E.; Khan, T. K.; Chong, P. L.-G. Two-photon fluorescence microscopy studies of bipolar tetraether giant liposomes from thermoacidophillic archaeabacteria Sulfolobus acidolocaldarius. Biophysical Journal. 2000, 79, 416425. (k) Khan, T. K.; Chong, P. L.-G. Studies of archaebacterial bipolar tetraether liposomes by perylene fluorescence. Biophysical Journal. 2000, 78, 1390-1399. (1) Mathai, J. C.; Sprott, G. D.; Zeidel, M. L. Molecular mechanisms of water and solute transport across archaebacterial lipid membranes. J. Biol. Chem. 2001, 276, 27266-27271. (m) Chong, P. L.-G.; Zein, M.; Khan, T. K.; Winter, R. Structure and conformation of bipolar tetraether lipid membranes derived from thermoacidophilic archaeon Sulfolobus acidocaldarius as revealed by small-angle X-ray scattering and high-pressure FT-IR spectroscopy. $J$. Phys. Chem. B. 2003, 107, 8694-8700. (n) Chong, P. L.-G.; Ravindra, R.; Khurana, M.; English, V.; Winter, R. Pressure perturbation and differential scanning calorimetric studies of bipolar tetraether liposomes derived from the thermoacidophilic archaeon Sulfolobus acidocaldarius. Biophysical Journal. 2005, 89, 1841-1849. (o) Brown, D. A.; Venegas, B.; Cooke, P. H.; English, V.; Chong, P. L.-G., Bipolar tetraether archaeosomes exhibit unusual stability against autoclaving as studied by dynamic light scattering and electron microscopy. Chem. Phys. Lipids. 2009, 159, 95-103. (p) Chong, P. L.-G.; Sulc, M.; Winter, R. Compressibilities and volume fluctuations of archaeal tetraether liposomes. Biophysical Journal. 2010, 99, 3319-3326. (q) Jeworrek, C.; Evers, F.; Erlkamp, M.; Brobelny, S.; Tolan, T.; Chong, P. L.-G.; Winter, R. Structure and phase behavior of archaeal lipid monolayers. Langmuir. 2017, 27, 13113-13121.

(9) Benvegnu, T.; Lemiègre, L.; Cammas-Marion, S. Archaeal lipids: Innovative materials for biotechnological applications. Eur. J. Org. Chem. 2008, 4725-4744.

(10) For a review of model tetraether lipid studies see until 2009: (a) Jacquemet, A.; Barbeau, J.; Lemiègre, L.; Benvegnu, T. Archaeal tetraether bipolar lipids: Structures functions and applications. Biochimie. 2009, 91, 711-717. For a selection of model tetraether lipid studies since 2009 see: (b) Jacquemet, A.; Vié, V.; Lemiègre, L.; Barbeau, J.; Benvegnu, T. Air/water interface study of cyclopentance-containing archaeal bipolar lipid analogues. Chemistry and Physics of Lipids. 2010, 163, 794-799. (c) Jacquemet, A.; Lemiègre, L.; Lambert, O.; Benvegnu, T. How the stereochemistry of a central cyclopentyl ring influences the self-assembling properties of archaeal lipid analogues: Synthesis and CryoTEM observations. J. Org. Chem. 2011, 76, 97389747. (d) Markowski, T.; Drescher, S.; Meister, A.; Blume, A.; Dobner, B. Structure-property relationships in a series of diglycerol tetraether model lipids and their lyotropic assemblies: the effect of branching topology and chirality. Org. Biomol. Chem. 2014, 12, 3649-3662. (e) Koyanagi, T.; Leriche, G.; Yep, A.; Onofrei, D.; Holland, G. P.; Holland, Mayer, M.; Yang, J. Effects of headgroups on small ion permeability across archaea-inspired tetraether lipid membranes. Chem. -Eur. J. 2016, 22,8074-8077. (f) Koyanagi, T.; Leriche, G.; Onofrei, D.; Holland, G. P.; Mayer, Michael, M.; Yang, J. Cyclohexane rings reduce membrane permability to small ions in archaea-inspired tetraether lipids. Angew. Chem. Int. Ed. 2016, 55, 1890-1893. (g) Dreshcer, S.; Otto, C.; Müller, S.; Garamus, V. M.; Garvey, C. J.; Grünert, Lischka, A.; Meister, A.; Blume, A.; Dobner, B. Impact of headgroup asymmetry and protonation state on the aggregation behavior of a new type of glycerol diether bolalipid. Langmuir. 2018, 34, 4360-4373. (h) Leriche, Manafirad, A.; Nguyen, S.; Bell, N. Patterson, J. P.; Thayumanavan, S.; Yang, J.; Dinsmore, A. D.; Gianneschi, N. C. Water permeability and elastic properties of an archaea inspired lipid synthesized by click chemistry. Chem. Mater. 2018, 30, 3618-3622. (i) Kim, Y. H.; Leriche, G.; Diraviyam, K.; Koyanagi, T.; Gao, K.; Onofrei, D.; Patterson, J.; Guha, A.; Gianneschi, N.; Holland, G. P.; Gilson, M. K.; Mayer, M.; Sept, D.; Yang, J. Entropic effects enable life at extreme temperatures. Sci. $A d v$. 2019, 5, 1-8.

(11) (a) Gabriel, J. L.; Chong, P. L.-G. Molecular modeling of archaebacterial bipolar tetraether lipid membranes. Chemistry and Physics of Lipids. 2000, 105, 193-200. (b) Nicolar, J. P. A molecular dynamics study of an archaeal tetraether lipid membrane: Comparison with a dipalmitoylphosphatidylcholine lipid bilayer. Lipids. 2005, 40, 
1023-1030. (c) Chugunov, A. O.; Volynsky, P. E.; Krylov, N. A.; Boldyrev, I. A.; Efremov, R. G. Liquid but durable: Molecular dynamics simulations explain the unique properties of archaeal-like membranes. Sci. Rep. 2014, 4, 7462. (d) Bulacu, M.; Périole, X.; Marrink, $\mathrm{S}$. J.; In silico design of robust bolalipid membranes. Biomacromolecules. 2012, 13, 196-205. (e) Youssefian, S.; Rahbar, N.; van Dessel, $\mathrm{S}$. Thermal conductivity and rectification in asymmetric archaeal lipid membranes. J. Chem. Phys. 2018, 148, 174901. (f) Dey, S.; Saha, J. Minimal coarse-grained modeling toward implicit solvent simulation of generic bolaamphiphiles. J. Phys. Chem. B. 2020, 124, 2938-2949.

(12) (a) Eguchi, T.; Arakawa, K.; Kakinuma, K.; Rapp, G.; Ghosh, S.; Nakatani, Y.; Ourisson, G. Giant vesicle from 72-membered macrocyclic phospholipid analgoues: Initiation of vesicle formation by molecular recognition between membrane components. Chem. Eur. J. 2000, 6, 3351-3358. (b) Arakawa, K.; Eguchi, T.; Kakinuma, K. Highly thermostable liposome form 72-membered macrocyclic tetraether lipid: Importance of 72-membered lipid for archaea to thrive under hyperthermal environments. Chem. Lett. 2001, 440-441.

(13) For additional reviews concerning the biosynthesis of GDGT0, see: (a) Koga, Y.; Morii, H. Biosynthesis of ether-type polar lipids in Archaea and evolutionary considerations. Microbiol. Mol. Biol. Rev. 2007, 71, 97-120. (b) Jain, S.; Caforio, A.; Driessen, A. J. M. Biosynthesis of archaeal membrane ether lipids. Frontiers in Microbiology. 2014, 5, 1-16. (c) Villanueva, L.; Sinninghe Damsté, J. S.; Schouten, S. A Re-evaluation of the archaeal membrane lipid biosynthetic pathway. Nature Reviews Microbiology. 2014, 12, 438-448.

(14) Zeng, Z.; Liu, X.-L.; Farley, K. R.; Wei, J. H.; Metcalf, W. W.; Summons, R. E.; Welander, P. V. GDGT cyclization proteins identify the archaeal sources of tetraether lipids in the ocean. Proc. Natl. Acad. Sci. USA. 2019, 116, 22505-22511.

(15) (a) Heathcock, C. H.; Finkelstein, B. L.; Aoki, T.; Poulter, C. D. Stereostructure of the archaebacterial C40 diol. Science. 1985, 229 , 862-864. (b) Heathcock, C. H.; Radel, P. A. Total synthesis of a slightly unnatural product. Confirmation of the stereostructure of the archaebacterial C40 diol by synthesis of a stereoisomer. J. Org. Chem. 1986, 51, 4322-4323. (c) 1,4- and 1,5- stereoselection by sequential aldol addition to $\alpha, \beta$-unsaturated aldehydes followed by Claisen rearrangement. Application to total synthesis of the vitamin E side chain and the archaebacterial C40 diol. J. Org. Chem. 1988, 53, 1922-1942.

(16) (a) Czeskis, B. A.; Alexeev, I. G.; Moiseenkov, A. M. The total synthesis of the archaebacterial $\mathrm{C}_{40}$-diol and its enantiomer based on (R)-5-acetoxy4-methylpentanoic acid. Russ. Chem. Bull. 1993, 42, 1246-1247. (b) Total synthesis of the archaebacterial $\mathrm{C}_{40}$-diol and its enantiomer based on $(R)-5$-acetoxy-4-methylpentanoic acid. Mendeleev Commun. 1993, 3, 93-96. (c) Attempts to identify how Czeskis acquired the $(R)-5-4$-methylpentanoic acid have thus far proven unsuccessful.

(17) (a) Eguchi, T.; Arakawa, K.; Terachi, T.; Kakinuma, K. Total synthesis of archaeal 36-membered macrocyclic diether lipid. J. Org. Chem. 1997, 62, 1924-1933. (b) Eguchi, T.; Ibaragi, K.; Kakinuma, K. Total synthesis of archaeal 72-membered macrocyclic tetraether lipids. J. Org. Chem. 1998, 63, 2689-2698. (c) Arakawa, K.; Eguchi, T.; Kakinuma, K. An olefin metathesis approach to 36- and 72- membered archaeal macrocyclic membrane lipids. J. Org. Chem. 1998, 63, 47414745 .

(18) For the synthesis of the hydrophobic core of cyclopentane containing GDGT's, see: Montenegro, E.; Gabler, B.; Paradies, G.; Seemann, M.; Helmchen, G. Determination of the Configuration of an Archaea membrane lipid containing cyclopentane rings by total synthesis. Angew. Chem. Int. Ed., 2003, 42, 2419-2421.

(19) (a) Bell, S.; Wüstenberg, B.; Kaiser, S.; Menges, F.; Netscher, T.; Pfaltz, A. Asymmetric hydrogenation of unfunctionalized, purely alkyl-substituted olefins. Science. 2006, 311, 642-644. (b) Wang, A.; Wüstenberg, B.; Pfaltz, A. Enantio- and diastereoselective hydrogenation of farnesol and O- protected derivatives: Stereocontrol by changing the $\mathrm{C}=\mathrm{C}$ bond configuration. Angew. Chem. Int. Ed. 2008, 47, $2298-2300$

(20) Yu, J. S.; Kleckley, T. S.; Wiemer, D. F. Synthesis of farnesol isomers via a modified Wittig procedure. Org. Lett. 2005, 7, 48034806.
(21) Barrero, A. F.; Quílez del Moral, J. F.; Mar Herrador, M.; Cortés, M.; Arteaga, Pilar.; Catalán, J. V.; Sánchez, E. M.; Arteaga, J. F. Solid-phase selenium-catalyzed selective allylic chlorination of polyprenoids: Facile syntheses of biologically active terpenoids. J. Org. Chem. 2006, 71, 5811-5814.

(22) For a general review of the stereochemical assignment of $\beta$ stereocenters via derivatization, see: (a) Manuel, J.; Quiñoá, Riguera, $\mathrm{R}$. The assignment of absolute configuration by NMR. Chem. Rev. 2004, 104, 17-118. For examples of the use of MTPA on a similar system see: (b) Finamore, E.; Minale, L.; Riccio, R.; Rinaldo, G.; Zollo, F. J. Org. Chem. 1991, 56, 1146-1153. (c) Tsuda, M.; Endo, T.; Kobayashi, J. Amphidinolide T, novel 19-membered macrolide from marine dinoflagellate Amphidinium sp. J. Org. Chem. 2000, 65, 1349-1352.

(23) Matsueda, T.; Xu, S.; Negishi, E.-I. A novel highly enantio- and diastereoselective synthesis of vitamin E side-chain. Tet. Lett. 2015, 56 , 3346-3348.

(24) Prinsell, M. R.; Everson, D. A.; Weix, D. J. Nickel-catalyzed, sodium iodide-promoted reductive dimerization of alkyl halides, alkyl pseudohalides, and allylic acetates. Chem. Commun. 2010, 46, 57435745 .

(25) For reviews of macrolactonizations in total synthesis, see: (a) Parenty, A.; Moreau, X.; Campagne, J.-M. Macrolactonizations in the total synthesis of natural products. Chem. Rev. 2006, 106, 911-939. (b) Parenty, A.; Moreau, X.; Niel, G.; Campagne, J.-M. Update 1 of: Macrolactonizations in the total synthesis of natural products. Chem. Rev. 2013, 113, PR1-PR40. (c) Li, Y.; Yin, X.; Dai, M. Catalytic macrolactonizations for natural product synthesis. Nat. Prod. Rep. 2017, 34, $1185-1192$.

(26) For a review of the reduction of carboxylic acid derivatives by catalytic hydrosilylation, see: Addis, D.; Das, S.; Junge, K.; Beller, M. Selective reduction of carboxylic acid derivatives by catalytic hydrosilylation. Angew. Chem. Int. Ed. 2011, 50, 6004-6011.

(27) (a) Inanaga, J.; Hirata, K,; Saeki, H.; Katsuki, T.; Yamaguchi, M. A rapid esterification by means of mixed anhydride and its application to large-ring lactonization. Bull. Chem. Soc. Jpn. 1979, 52, 19891993. (b) For an example of a Yamaguchi esterification-macrolactonization, see: Sato, T.; Aoyagi, S.; Kibayashi, C. Enantioselective total synthesis of (+)-azimine and (+)-carpaine. Org. Lett. 2003, 5, 38393842. (c) Corey, E. J.; Nicolau, K. C. Efficient and mild lactonization method for the synthesis of macrolides. J. Am. Chem. Soc. 1974, 96, 5614-5616. (d) For an example of a Mitsunobu macrolactonization in synthesis see: Emmer, G.; Grassberger, M. A.; Meingassner, J. G.; Shulz, G.; Schaude, M. Derivatives of a novel cyclopeptolide. 1. Synthesis, antifungal activity, and structure-activity relationships. J. Med. Chem. 1994, 37, 1908-1917.

(28) (a) Fürstner, A.; Albert, M. Mlynarski, J.; Matheu, M. A concise synthesis of the fully functional lactide core of cycloviracin B with implications for the structural assignment of related glycolipids. J. Am. Chem. Soc. 2002, 124, 1168-1169. (b) Fürstner, A.; Mlynarski, J.; Albert, M. Total synthesis of the antiviral glycolipid cycloviracin $\mathrm{B}_{1} . J$. Am. Chem. Soc. 2002, 124, 10274-10275. See also: (c) Takahashi, S.; Souma, K.; Hashimoto, R.; Koshino, H.; Nakata, T. Synthetic studies on microviracin A: A rapid construction of $\mathrm{C}_{42}$ macrocyclic dilactone corresponding to the core. J. Org. Chem. 2004, 69, 4509-4515.

(29) (a) Isobe, T.; Ishikawa, T. 2-Chloro-1,3-dimethylimidazolinium chloride. 1. A powerful dehydrating equivalent to DCC. J. Org. Chem. 1999, 64, 6984-6988. (b) Garcia, D. M.; Yamada, H.; Hatakeyama, S.; Nishizawa, M. Total synthesis of arthrobacilin A. Tet. Lett. 1994, 35, $3325-3328$.

(30) (a) Sakai, N.; Morya, T.; Konakahara, T. An efficient one-pot synthesis of unsymmetrical ethers: A directly reductive deoxygenation of esters using an $\mathrm{InBr}_{3} / \mathrm{Et}_{3} \mathrm{SiH}$ catalytic system. J. Org. Chem. 2007, 72, 5920-5922. (b) Sakai, N.; Usui, Y.; Moriya, T.; Ikeda, R.; Konakahara, T. One-pot sequential synthesis of ethers from an aliphatic carboxylic acid and an alcohol by indium-catalyzed deoxygenation of an ester. Eur. J. Org. Chem. 2012, 4603-4608.

(31) Synthetic 1: $[\alpha]_{\mathrm{D}}^{23}=+7.49\left(\mathrm{c}=0.2, \mathrm{CHCl}_{3}\right)$; isolated 1, $[\alpha]_{\mathrm{D}}{ }^{23}$ $=+8.3\left(\mathrm{c}=10, \mathrm{CHCl}_{3}\right)$ : De Rosa, M.; Gambacorta, A.; Nicolaus, B.; Sodano, S.; Bu'Lock, J. D. Structural regularities in tetraether lipids of Caladriella and their biosynthetic and phyletic implications. Phytochemistry, 1980, 19, 833-836. 
(32) Gunther, G.; Malacrida, L.; Jameson, D. M.; Gratton, E.; Sánchez, S. A. LAURDAN since Weber: The quest for visualizing membrane heterogeneity. Acc. Chem. Res. 2021, 54, 976-987. 